\title{
Índices de vulnerabilidade à erosão das praias da Ilha de Itamaracá, litoral norte de Pernambuco, Brasil.
}

\author{
Vulnerability indices to erosion of beaches of Ilha de Itamaracá, coastal \\ north Pernambuco, Brazil.
}

\author{
Carlos Fabrício Assunção da Silva ${ }^{1}$, Bruno Ferreira ${ }^{2}$, Eduardo Paes Barreto ${ }^{2}$, Maria das Neves

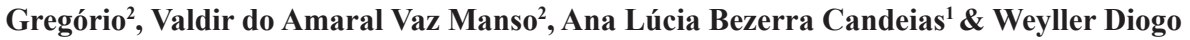 \\ Albuquerque Melo ${ }^{1}$
}

\begin{abstract}
RESUMO
As praias do Forte Orange, Pilar e Jaguaribe estão localizadas a $50 \mathrm{~km}$ ao norte da cidade do Recife, no município da Ilha de Itamaracá. Nas últimas décadas apresentou um rápido crescimento urbano, ligado principalmente às atividades turísticas da orla. As construções irregulares e empreendimentos turísticos na zona da pós-praia diminui a capacidade de transporte dos sedimentos, e sua deposição no sistema praial interferindo na morfodinâmica do ambiente e, assim, promove a instalação da erosão marinha. O estudo teve como objetivo identificar e avaliar através de índices quantitativos e qualitativos o grau de vulnerabilidade à erosão costeira. Para isto foi levado em consideração as atividades humanas e as características naturais da praia. A metodologia foi realizada a partir do mapeamento de toda a orla. Identificou-se cada setor, por células e os índices do grau de vulnerabilidade foram definidos como: alto, médio e baixo. No setor 1 (Sul) observou-se um grau moderado de vulnerabilidade à erosão, este apresentou uma pós-praia desenvolvida com certa tendência a progradação. O setor 2 (Centro) recebeu um alto grau de vulnerabilidade, onde parte da pós-praia foi totalmente ocupada, apresentou estruturas rígidas de proteção à costa. $\mathrm{O}$ setor 3 (Norte) recebeu também alto grau de vulnerabilidade, este setor apresentou boa parte da pós-praia ocupada com construções inadequadas e um pequeno trecho deste ambiente desenvolvido, com tendência a progradação. A identificação de setores por meio do grau de vulnerabilidade mostrou ser uma importante ferramenta de análise e fornece subsídios a política públicas e ao gerenciamento costeiro.
\end{abstract}

Palavras-chave: Praias, Construções, Vulnerabilidade, Progradação, Ilha de Itamaracá, Erosão.

\begin{abstract}
Forte Orange, Pilar and Jaguaribe beaches are located on Itamaracá Island, $50 \mathrm{~km}$ North of Recife. In the last few decades these beaches have experienced rapid urban growth, connected to the tourism activities in the area. The irregular constructions and the tourist business in the area have decreased sediment transport capacity, along with its deposition in the beach system. This interference in the beach system's morph dynamics over the time, has caused erosion in the study area. This work aims to identify and analyze the degree of erosion vulnerability. Human activities and the beach's natural characteristics were considered. During the mapping of the area sectors by cells were identified and vulnerability tables were assigned, defined as: high, medium and low. Sector 1 (South) presented a moderate degree of vulnerability to erosion, since it had a developed post-beach tending to progradation. Sector 2(Center) presented a high degree of vulnerability, where a large part of the postbeach was totally occupied, presenting only protection structure against erosion. Sector 3 (North) also presented a high degree of vulnerability, a large part of this sector has the post-beach totally occupied by inappropriate buildings (bars and residences), and a small part of this area has been developed tending to progradation. Therefore, the sector identification through these quantitative and semi qualitative indices proved to be an important tool, being one more subsidy to the coastal management.
\end{abstract}

Keywords: Beaches, Buildings, Vulnerability, Progradation, Island of Itamaracá, Erosion.

Recibido el 30 de mayo de 2016; aceptado el 02 de noviembre de 2016

\footnotetext{
1 Universidade Federal de Pernambuco Centro de Tecnologia e Geociências - CTG Departamento de Engenharia Cartográfica - DECart Av. Prof. Moraes Rego, 1235 - Cidade Universitária, Recife - PE - CEP: 50670-901. carlosfew@outlook.com

2 Universidade Federal de Pernambuco Centro de Tecnologia e Geociências - CTG Departamento de Geologia DGEO Av. Acadêmico Hélio Ramos s/n- Cidade Universitária, Recife - PE - CEP: 50740-530
} 


\section{INTRODUÇÃO}

O estado de Pernambuco está localizado na porção mais oriental da Região Nordeste do Brasil. Essa unidade do território brasileiro possui uma faixa costeira de aproximadamente $187 \mathrm{~km}$ de extensão, distribuída na direção de norte a sul. $\mathrm{O}$ Estado de Pernambuco tem uma grande importância econômica e sociocultural, e vem apresentando, ao longo das últimas décadas graves problemas ambientais, gerados em grande parte, pelo processo histórico da ocupação desordenada.

A ocupação desordenada do litoral pernambucano promove, entre outros, o desequilíbrio dos ambientes praiais (ARAÚJO et al. 2007). Dentre estes, o mais evidente está relacionado à erosão marinha progressiva, cujos efeitos se fazem sentir predominantemente na região da pós-praia. A ação dos processos marinhos deixa um rastro de destruição e graves consequências para a população e nas atividades econômicas desenvolvidas no local.

Ao setorizar-se o litoral de Pernambuco de norte para o sul, verifica-se que há características bem distintas entre eles, passando pelo processo de ocupação e formas de uso, desenvolvidos ao longo das últimas décadas. O Litoral Norte do Estado apresenta processos erosivos associados não apenas às condições hidrodinâmicas, mas vem sendo fortemente modificados e/ou intensificados pelas ações antrópicas, mais especificamente, à ocupação desordenada na região superior do sistema praial (MANSO, 1997; MENDONÇA et al. 2014).

Diante desse cenário, fortemente marcado pela relação ocupação e impactos gerados ao ambiente costeiro, faz-se necessário analisar e classificar por setores os impactos gerados pela ocupação antrópica. Nesse sentido, a definição e a quantificação do grau de vulnerabilidade à erosão costeira permite identificar riscos potenciais a esses ambientes, bem como, apontar áreas prioritárias para a concentração de estudos e realização de ações de manejo sob uma óptica de conservação ambiental e mitigação de impactos (CAPOBIANCO et al. 1999).

Este tipo de estudo consiste, portanto, em uma ferramenta analítica poderosa na descrição dos estados de susceptibilidade nos sistemas físicos e aos danos neles ocorridos. Com isso, os resultados obtidos podem ser capazes de orientar os gestores e a sociedade na tomada de decisões, bem como, auxiliar no desenvolvimento de ações no sentido de reduzir os riscos ambientais (ADGER, 2006).

Embora não exista uma definição unânime, o termo vulnerabilidade vem sendo intensamente utilizado e caracterizado nos estudos disponíveis, deixando transparecer que há um amplo leque de definições e abordagens conceituais aplicáveis. O risco a vulnerabilidade apresenta vários significados ao termo, o novo conceito proposto corresponde ao risco do lugar (CUTTER, 1996). A Vulnerabilidade como exposição ao risco/perigo: foca na probabilidade de exposição (risco tecnológico/biofísico), categorizada como condição pré-existente incluíndo a vulnerabilidade natural (LIMA \& AMARAL, 2013).

A análise dos processos da evolução do ambiente praial, a médio e a longo prazo, fornece as informações necessárias para a identificação da distribuição espacial do grau de vulnerabilidade de uma praia. $\mathrm{Na}$ análise da classificação, os dados obtidos podem representar um importante instrumento para a gestão ambiental dos municípios costeiros, na medida em que revela as tendências a erosão ou não das praias.

Geralmente o processo erosivo está diretamente relacionado com as formas de uso e ocupação da faixa litorânea. Além disso, tais análises podem subsidiar o entendimento da dinâmica sedimentar, indicando os pontos estratégicos para a 
compreensão dos processos erosivos e/ou deposicionais para a tomada de decisões dos órgãos competentes.

A área de estudo, está situada no Litoral Norte de Pernambuco na Ilha de Itamaracá (Fig.1). O município, homônimo, integra a Região Metropolitana do Recife, capital do Estado. Sua sede municipal localiza-se à $50 \mathrm{~km}$ da capital e o seu acesso se faz pela BR 101 à norte e pela $\mathrm{PE} 035$. A economia municipal é fortemente ligada ao setor turístico, principalmente ao lazer, tendo como principais atrativos a beleza cênica de suas praias e importantes monumentos históricos presentes na ilha.

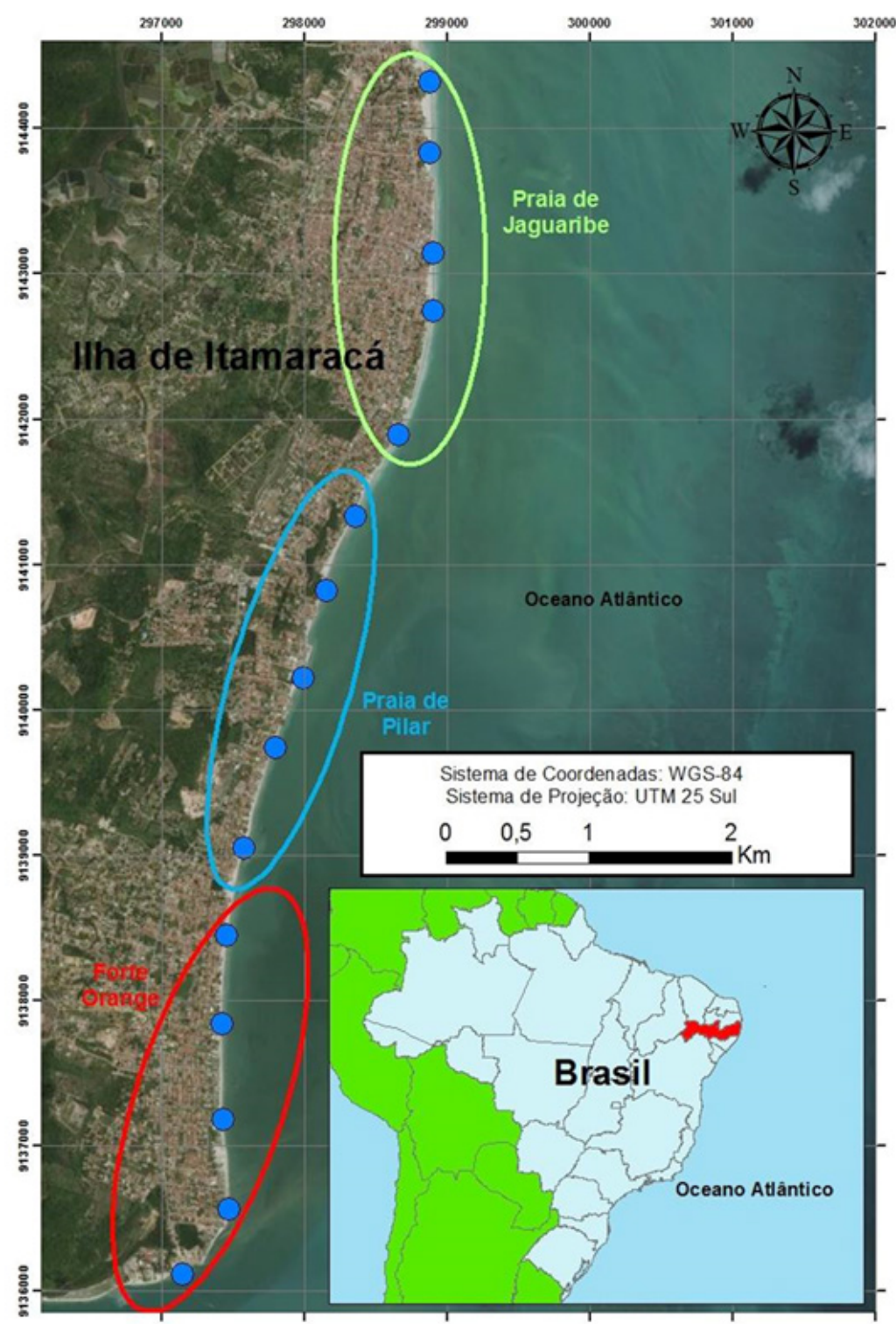

Fig. 1. Localização da área de estudo. (Setor 1 Praia do Forte Orange, Setor 2 Praia do Pilar, Setor 3 Praia de Juguaribe)

Fig. 1. Area of study. (Section 1, Forte Orange beach; Section 2, Pilar beach; Section 3, Jaguaribe beach). 
A Ilha de Itamaracá abrange uma área aproximada de $65,411 \mathrm{~km} 2$, individualizada do continente por um estreito canal de maré, Canal de Santa Cruz, com o eixo principal de distribuição na direção norte sul, paralelo a linha de praia. Do ponto de vista climático apresenta, segundo a classificação de Koppen, clima tropical típico, quente e úmido do tipo As', altas temperaturas e uma umidade constante ao longo do ano. As temperaturas médias estão sempre acima dos $18^{\circ} \mathrm{C}$. As temperaturas máximas chegam aos $34^{\circ} \mathrm{C}$, e as mínimas a $20^{\circ} \mathrm{C}$ (MONTES, 1996).

O município apresenta uma estação seca no verão e uma de chuvas durante o inverno antecipadas para o outono. A estação seca ocorre entre os meses de setembro a fevereiro, e a estação chuvosa entre os meses de março a agosto. A precipitação média é superior a $100 \mathrm{~mm} / \mathrm{m}$, podendo atingir 400 $\mathrm{mm} / \mathrm{m}$, as precipitações anuais extrapolam os $2.000 \mathrm{~mm} \mathrm{e}$, taxa de evaporação é inferior à de precipitação, havendo um balanço hídrico anual sempre positivo.

O município de Itamaracá tem diversos problemas ambientais, como: a intensificação da erosão marinha, destruição dos atrativos paisagísticos e a perda da balneabilidade em algumas praias. Tais perdas estão relacionadas às formas de apropriação e uso do espaço local e apresentam inúmeros elementos que ajudam a intensificar os problemas ambientais, tais como: construções desordenadas localizadas na linha de praia (moradias fixa e de uso sazonal), estabelecimentos comerciais, hotéis, lançamento de efluentes, deposição de resíduos sólidos, entre outros, no ambiente praial. Sendo necessária uma avaliação do grau de vulnerabilidade à erosão costeira na Ilha.

Neste sentido, o estudo buscou reconhecer as tendências evolutivas da vulnerabilidade à erosão costeira nas praias do Município de Itamaracá. Ação emergente se faz necessária, uma vez que agrega a finalidade de identificar pontos mais suscetíveis ao processo erosivo e à sua intensificação, em razão da influência antrópica. Este estudo também servirá de base a novas pesquisas e para a tomada de decisões na gestão da ilha.

\section{MATERIAIS E MÉTODOS}

As informações utilizadas neste trabalho foram obtidas durante caminhamentos realizados nos dias 15 de outubro de 2013, ao longo do arco praial das praias da Ilha de Itamaracá.

O caminhamento foi realizado com o uso de um GPS GARMIN. Os setores ou células da praia foram individualizados, para a identificação do grau de vulnerabilidade à erosão nas praias do Forte Orange, Praia do Pilar e a Praia de Jaguaribe, segundo o método proposto por DAL \& SIMEONI (1994); COUTINHO et al. (1997); COELHO (2006); MARCOMINI \& LÓPEZ (2007) em REIS et al. 2008, ROCHA et al. 2008. O método consiste na observação de algumas características da praia, como a presença de estruturas de contenção e o grau de ocupação da póspraia e do estirâncio.

Para à determinação do grau de vulnerabilidade à erosão, de acordo com a classificação de MARCOMINI \& LÓPEZ (2007) em REIS et al. 2008 (Tabela 1), foi determinado em função das interações humanas e as características naturais da praia conforme a seguir: a) no ambiente praial foi considerado a presença ou ausência da região da pós praia. b) estruturas de proteção natural (presença ou ausência de estruturas rígidas, como por exemplo, os beachrocks ou rochas praiais); c) desenvolvimento urbano (grau de ocupação); e d) estruturas artificiais de proteção (presença ou ausência e posicionamento). Para cada um dos parâmetros considerados foram atribuídos classes e pesos. Os pesos aumentam de acordo com o impacto negativo da ausência ou presença dos elementos propostos. 
Neste estudo, o termo grau de vulnerabilidade à erosão costeira foi utilizada para identificar o comportamento da praia ou dos trechos estudados a sofrer danos em relação ao seu estado de equilíbrio, em relação aos fatores naturais ou antrópicos, e a sua classificação em setores (células), em razão dos parâmetros citados anteriormente (Tabela 1). Sendo assim, foram somados os pesos, os quais foram distribuídos valores de zero a três estabelecidos segundo MARCOMINI \& LÓPEZ (2007) em REIS et al. 2008, resultando no nível de risco da praia à erosão coteira. Por fim, a soma destas características gerou uma tabela definindo o grau efetivo de vulnerabilidade, em uma escala de 0 a 8 , variando do menor (baixo) para o maior grau (alto) de vulnerabilidade (Tabela 2).

Tabela 1. Parâmetros, Classes, Pesos e definições Para a determinaÇão do grau de VULNERABILIDADE À EROSÃo COSTEIRA (FONTE: MODIFICADO DE MARCOMINI \& LÓPEZ (2007) EM REIS ET AL. (2008).

TABle 1. Parameters, Classes, Weights AND Definitions FOR THE Determination OF THE VULNERABILITY DEGREE OF COASTAL EROSION. (MODIFIED FROM DE MARCOMINI \& LÓPEZ (2007) IN REIS ET AL. (2008))

\begin{tabular}{|c|c|c|c|c|}
\hline & PARÂMETROS & CLASSES & PESOS & DEFINIÇÕES \\
\hline \multirow{3}{*}{ I } & \multirow{3}{*}{$\begin{array}{l}\text { Presença ou } \\
\text { ausência da pós- } \\
\text { Praia }\end{array}$} & Ausente & 3 & Substituídas pela urbanização \\
\hline & & Presente & 2 & Conservadas, com pouca urbanização \\
\hline & & Presente & 1 & Bem conservadas, sem ocupação urbana \\
\hline \multirow{2}{*}{ II } & \multirow{2}{*}{$\begin{array}{l}\text { Estruturas de } \\
\text { Proteção natural }\end{array}$} & Ausente & 1 & $\begin{array}{l}\text { Sem a presença de proteção natural (beachrocks ou } \\
\text { rochas praiais) }\end{array}$ \\
\hline & & Presente & 0 & $\begin{array}{l}\text { Presença de proteção natural (beachrocks ou rochas } \\
\text { praiais) }\end{array}$ \\
\hline \multirow{3}{*}{ III } & \multirow{3}{*}{$\begin{array}{l}\text { Desenvolvimento } \\
\text { Urbano }\end{array}$} & Baixo & 1 & Baixa concentração da área costeira ocupada \\
\hline & & Moderado & 2 & Média concentração da área costeira ocupada \\
\hline & & Alto & 3 & Alta concentração de ocupações da área costeira ocupada \\
\hline \multirow{2}{*}{ IV } & \multirow{2}{*}{$\begin{array}{l}\text { Estruturas } \\
\text { Artificiais }\end{array}$} & Ausentes & 0 & $\begin{array}{l}\text { Sem estruturas de proteção ou contenção à erosão } \\
\text { marinha. }\end{array}$ \\
\hline & & Presentes & 1 & $\begin{array}{l}\text { Com estruturas de proteção ou contenção à erosão } \\
\text { marinha. }\end{array}$ \\
\hline
\end{tabular}

O significado ambiental da atribuição do grau de vulnerabilidade está representado na tabela 2 e foi caracterizado conforme descrito abaixo 1 - alto; 2 - moderado; 3 - Baixo, descritos a seguir, segunda as atribuições de cada peso.

\section{(1) Grau de Vulnerabilidade Alto -} ausência de pós-praia e estirâncio reduzido; praia com tendência erosiva, presença de estruturas artificiais de proteção e alta concentração de ocupação urbana;

(2) Grau de Vulnerabilidade Moderado - praia com frágil estabilidade ou ligeira tendência erosiva; setores de pós-praia e estirâncio pouco desenvolvidos; presença de obras de contenção e média concentração urbana; 
(3) Grau de Vulnerabilidade Baixo - praia com tendência à progradação; pós-praia e estirâncio bem desenvolvidos; ausência de obras de contenção; desenvolvimento urbano incipiente.

Neste estudo, o grau de vulnerabilidade à erosão costeira está conceituado como a propensão de uma determinada área a sofrer danos devido à ação de agentes naturais ou antrópicos, podendo ser determinada em função da estabilidade e das características da praia, resultando, assim, em uma classificação em setores (células), com maior ou menor tendência à erosão, a partir da seleção de alguns parâmetros (variáveis).

Tabela 2. Classificação Quanto ho grau de vUlnerabilidade À erosão costeira.

TABLE 2. ClasSification OF THE VULNERABILITY DEGREE OF COASTAL EROSION.

\begin{tabular}{|l|l|}
\multicolumn{2}{|c|}{ GRAU DE VULNERABILIDADE À EROSÃO COSTEIRA } \\
\hline Alto & Entre 7 e 8 \\
\hline Moderado & Entre 5 e 6 \\
\hline Baixo & Entre 0 e 4 \\
\hline
\end{tabular}

\section{RESULTADOS E DISCUSSÃO}

A classificação do grau de vulnerabilidade à erosão costeira dos setores do ambiente praial da Ilha de Itamaracá ocorreram por meio de parâmetros e pesos, os quais resultaram na distribuição descrita da tabela 3 .

\section{Tabela 3. ClassificaÇão da VUlnerabilidade À erosão Costeira POR Meio dos ParâMetros E CLASSES.}

TABLE 3. CLASSIFICATION OF THE VULNERABILITY DEGREE OF COASTAL EROSION CONSIDERING PARAMETERS AND CLASSES.

\begin{tabular}{|c|c|c|c|c|c|}
\hline \multirow{2}{*}{ Setores } & \multicolumn{4}{|c|}{ Parâmetros/Pesos } & \multirow{2}{*}{$\begin{array}{l}\text { Soma dos Pesos } \\
= \\
\text { Vulnerabilidade }\end{array}$} \\
\hline & I & II & III & IV & \\
\hline SETOR 1 & 2 & 1 & 2 & 1 & 6 \\
\hline SETOR 2 & 3 & 1 & 2 & 1 & 7 \\
\hline SETOR 3 & 3 & 1 & 3 & 1 & 8 \\
\hline
\end{tabular}

Os resultados obtidos se encontram representados nas Figuras 2 a 10. No setor 1, a soma dos pesos resultou em um grau de vulnerabilidade no valor 6. Este valor representou um moderado grau de vulnerabilidade. Para o setor 2 a soma dos pesos, o grau foi representado pelo valor 7. No setor 3 foi observado um grau de valor 8 , constatando um alto grau de vulnerabilidade.

\section{Setor 1, Praia do Forte Orange.}

Este setor compreende a praia do Forte Orange, localizado ao sul da Ilha de Itamaracá (Fig. 2), entre o Forte Orange e 
a praia do Pilar, apresentou um ambiente sem obras de contenção e com um pontal arenoso próximo ao canal do Santa Cruz. Ao longo do arco praial foi observado a presença de uma planície de maré a qual fica exposta durante a maré baixa. Neste setor foi considerado um moderado grau de vulnerabilidade à erosão. Ao Sul deste setor foi observado uma distribuição espacial no ambiente praial a ausência da região da pós-praia, sendo vulnerável aos processos erosivos, bem como, uma área relativamente preservada. Neste setor, a área ao norte da praia do Forte Orange foi intensamente ocupada pela ação antrópica, onde foram identificadas construções inadequadas, representadas por barracas e bares na região da póspraia. Na parte central da praia, ainda se encontram pequenos trechos representados pela vegetação natural, o qual vem sendo retirada pela população local.

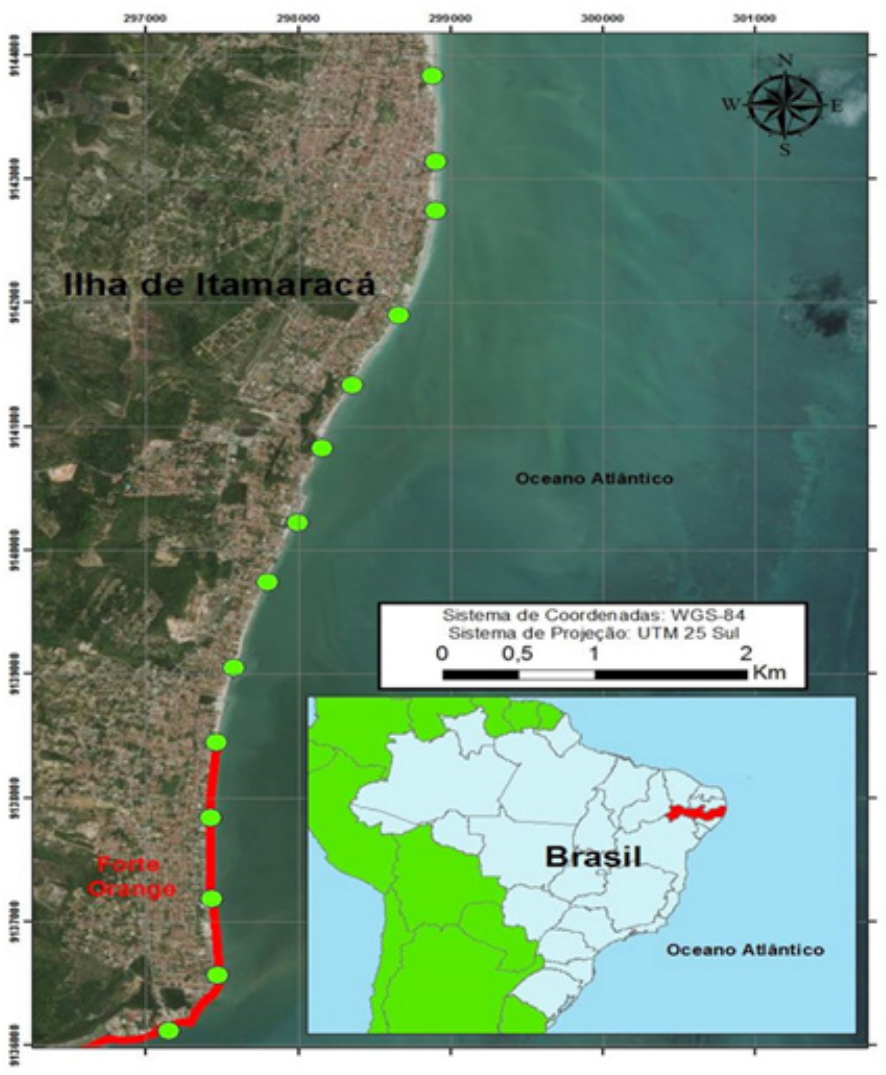

Fig. 2. Setor 1 localizado na Praia de Forte Orange.

Fig. 2. Section 1, Forte Orange beach 


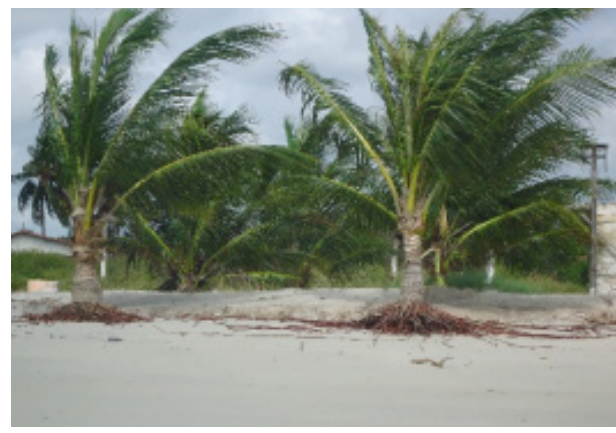

Fig. 3. Raízes de árvores expostas na Praia do Forte Orange

Fig. 3. Exposed tree roots in Forte Orange beach.

\section{Setor 2 (praia do pilar)}

Este setor compreende a praia do Pilar, ao norte da praia do Forte Orange e ao sul da praia de Jaguaribe. Se caracteriza por uma praia com obras de contenção marinha e construções residenciais, sendo algumas dessas desocupadas pelos proprietários devido ao processo erosivo. Apresentando assim, um ambiente praial com ausência da pós praia e a região da praia pouco desenvolvida. Quase todo o setor está representado por um alto grau de vulnerabilidade à erosão marinha. Apresentou uma distribuição espacial semelhante ao setor 1 , com a presença ou ausência da região da pós-praia e estirâncio reduzido. Entretanto, a praia do Pilar tem uma tendência erosiva, sendo constatado ao longo deste setor, estruturas artificiais de proteção à erosão costeira (muros de arrimos e enrocamentos) e uma alta concentração de ocupação urbana. Foi também observada a presença de bares e residências, situados a poucos metros da porção superior do estirâncio.

Vale ressaltar que em alguns trechos da praia, e da pós-praia ainda possui uma vegetação natural. Por outro lado,

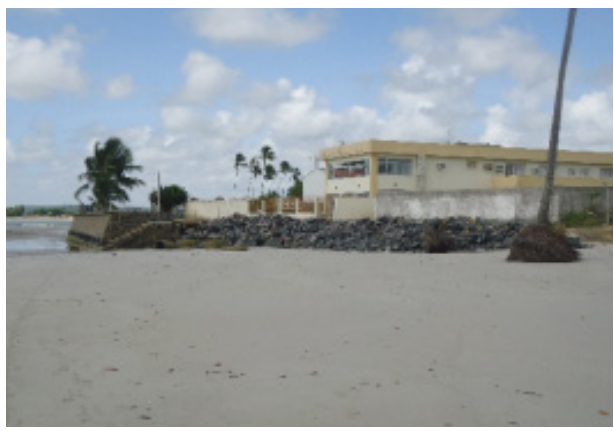

Fig. 4. Enrocamento construído à revelia na Praia do Forte Orange.

Fig. 4. Built stone in Forte Orange beach.

nos trechos observados com estruturas de proteção do tipo enrocamento, os quais foram construídos sem levar em consideração a morfodinâmica do sistema praial. Este processo ocorre especialmente ao sul do setor 2, sendo possível verificar que tais estruturas estão acelerando e intensificando os processos de erosão. 


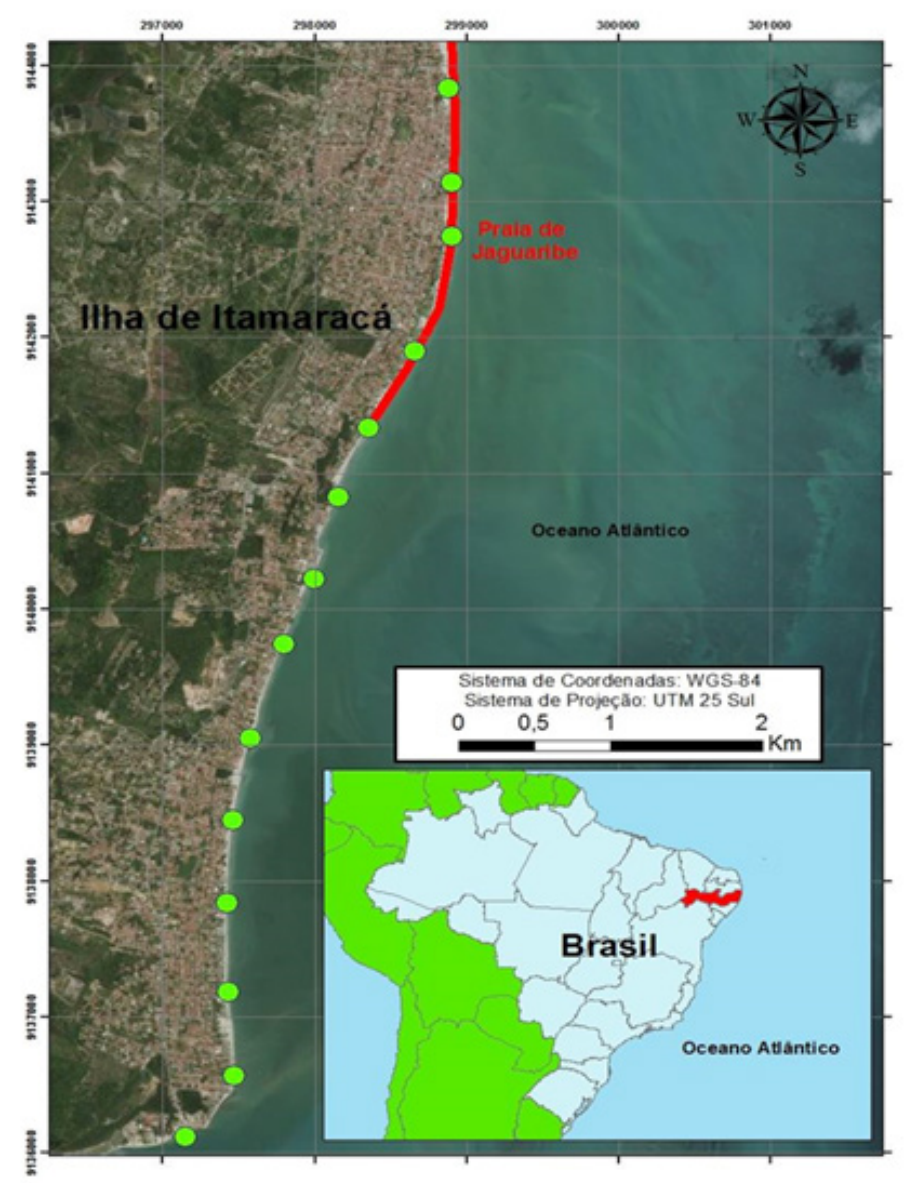

Fig. 5. Setor 2 localizado na Praia do Pilar.

Fig. 5. Section 2, Pilar beach.

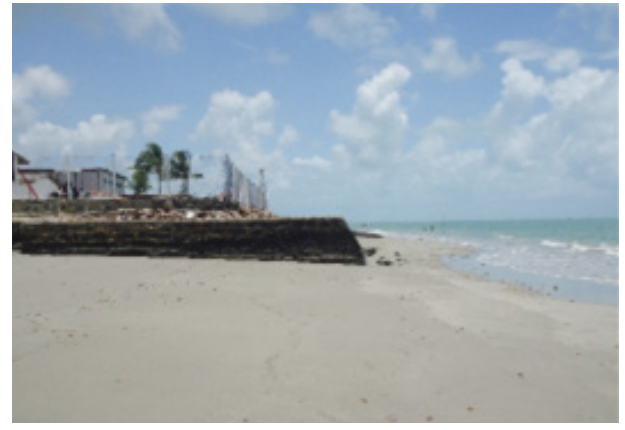

Fig. 6. Setor 2 na Praia do Pilar.

Fig. 6. Section 2, Pilar beach.

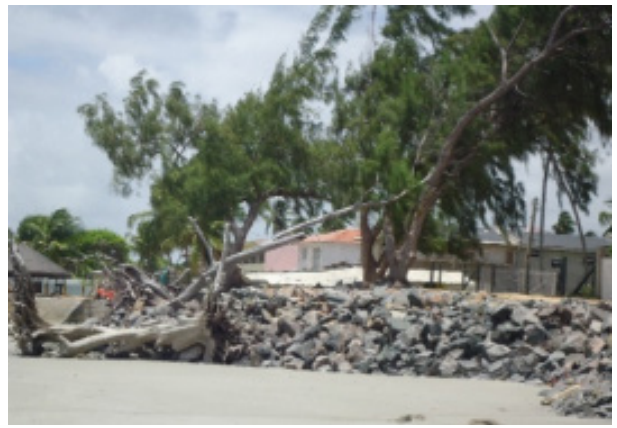

Fig. 7. Setor 2 na Praia do Pilar.

Fig. 7. Section 2, Pilar beach. 


\section{Setor 3 (Praia de Jaguaribe)}

Este setor compreende a praia de Jaguaribe, localizado ao norte da Ilha de Itamaracá, este trecho corresponde ao setor mais antropizado, com ambiente praial pouco desenvolvido ao sul desse trecho. Entretanto ao norte da praia de Jaguaribe foi observado um ambiente praial menos urbanizado e a região da praia com uma maior largura, a presença de estruturas naturais (beachrocks). Os segmentos referentes às imagens da Figura 3 estão situados na praia de Jaguaribe, e se encontram localizados ao norte da Ilha de Itamaracá. O setor 3 apresentou um grau de vulnerabilidade alta. Entretanto, parte do trecho da praia de Jaguaribe apresentou a região da pós-praia bem desenvolvida e uma tendência a progradação. Trata-se de um trecho protegido naturalmente por estruturas rochosas (beachrocks).
Ao setor 3 foi atribuído um alto grau de vulnerabilidade, em razão de alguns trechos observados ficarem situados a poucos metros da porção superior do estirâncio, sendo observado casas de veraneios em áreas inadequadas, obras de contenção de pequeno e grande porte na parte superior do ambiente praial.

Vale ressaltar que em todos os setores estudados, mesmo os que apresentaram um grau moderado de vulnerabilidade, é preocupante o prognóstico, tendo em vista que a deriva litorânea nesta região ocorre de Sul para Norte (LIRA et al. 2010). Assim, diante das construções de estruturas rígidas (proteção e/ou contenção) em determinados setores, o processo de erosão poderá migrar ou ser incorporado as praias adjacentes.

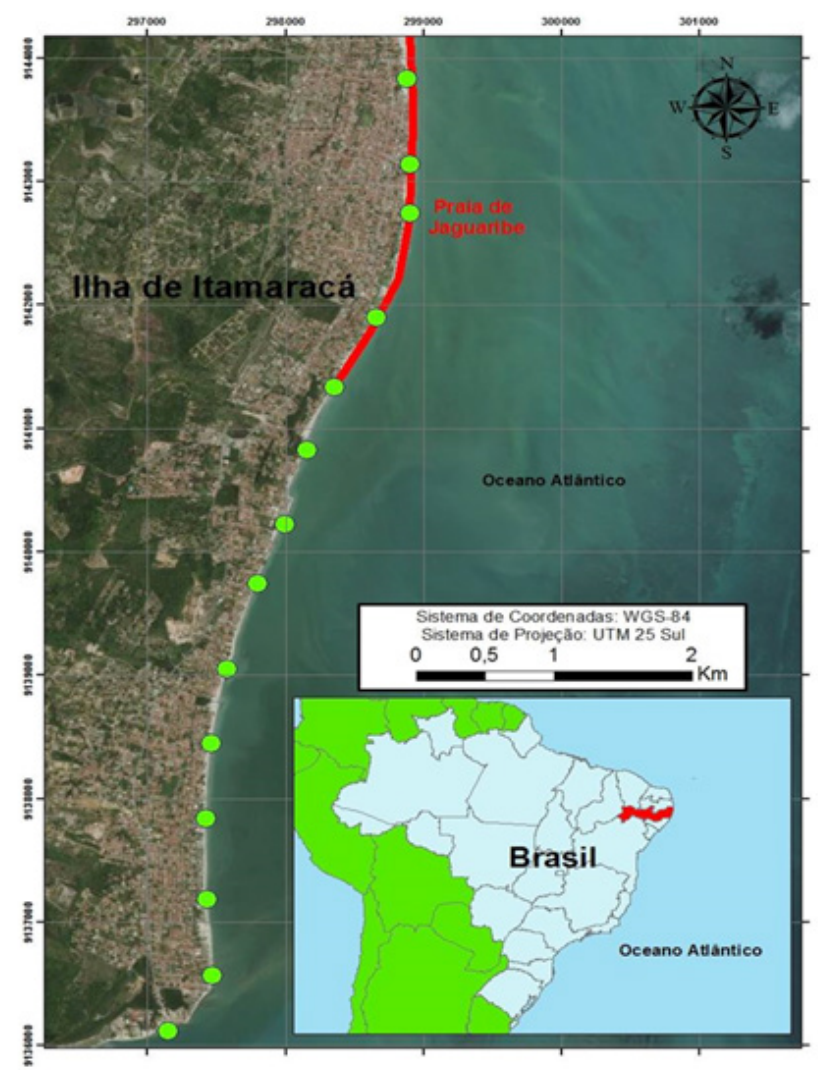

Fig. 8. Setor 3 localizado na Praia do Jaguaribe.

Fig. 8. Section 3, Jaguaribe beach. 


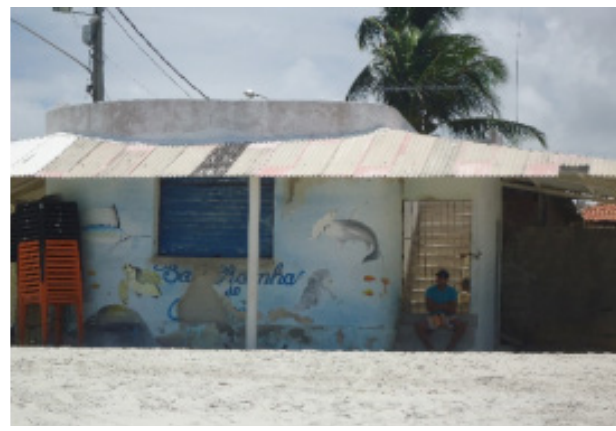

Fig. 9. Muro de contenção na Praia do Pilar.

Fig. 9. Retaining wall in Pilar beach.

\section{CONCLUSÕES}

No estudo realizado foram observadas a presença de construções inadequadas na região da pós-praia. Pode ser citado como exemplo: casas de veraneios, hotéis, barracas. Devido ao encurtamento da praia para os banhistas, mais precisamente no setor 2 (praia do Pilar) e o setor 3 (praia de Jaguaribe) há consequente desconforto aos danos causados às espécies marinhas que habitam a região superior do ambiente marinho.

Vale ressaltar a necessidade de um maior monitoramento e controle do sistema praial por parte do poder público em averiguar os locais de construções, antes destas serem erguidas.

A análise realizada na Ilha de Itamaracá foi desenvolvida a partir do mapeamento de toda a orla, e das atribuições de pesos aos índices do grau de vulnerabilidade, os quais foram definidos como: alto, médio e baixo. Para o setor 1 (Sul) observou-se um moderado grau de vulnerabilidade à erosão. Este apresentou uma região da pós-praia desenvolvida com certa tendência a progradação. $\mathrm{O}$ setor 2 (Centro) recebeu um alto grau de vulnerabilidade, em razão, de grande parte da pós-praia está totalmente ocupada por construções irregulares, apresentando estruturas rígidas de proteção à erosão. E

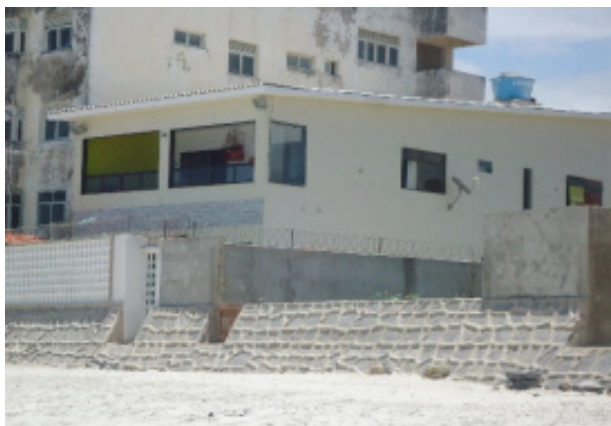

Fig. 10. Construções na área praial na Praia do Pilar.

Fig. 10. Buildings in Pilar beach.

o setor 3 (Norte) recebeu também alto grau de vulnerabilidade, boa parte deste setor também possui características semelhantes ao setor 2 , sendo observado a região da póspraia totalmente ocupada com construções inadequadas (bares e residências). Entretanto este setor apresentou um pequeno trecho do ambiente da pós-praia desenvolvido, com tendência a progradação.

A identificação de setores por meio de índices quantitativos e qualitativos mostrouse ser uma importante ferramenta para à análise da instalação de processos erosivos no sistema praial, bem como, fornecer subsídios a aplicação de políticas públicas e gerenciamento costeiro.

\section{REFERÊNCIAS}

ADGER, W. N. (2006). Vulnerability. Global Environmental Change, 16, 268-281.

ARAÚJO, M. C. B., SOUZA, S. T., CHAGAS, A. C. O., BARBOSA, S. C. T., \& COSTA, M. F. (2007). Análise da ocupação urbana das praias de Pernambuco, Brasil. Gestão Costeira Integrada, 7(2), 97104.

CAPOBIANCO, M., DEVRIEND, H. J., NICHOLLS, R. J., \& STIVE, M. J. F. (1999). Coastal area impact and 
vulnerabiliry assessment: the point of view of a morphodynamic modeler. Journal of Coastal Research, Royal Paml Beach, Florida, 15 (3), 701-716.

COELHO, C. (2006). Riscos de exposição de frentes urbanas para diferentes intervenções de defesa costeira. (404 p.). Tese de Doutorado, Universidade de Alveiro, Portugal.

COUTINHO, P.N., LIMA, A.T.O., QUEIROZ, C.M., FREIRE, G.S.S., ALMEIDA, L.E.S.B., MAIA, L.P., MANSO, V.A.V., BORBA, A.L.S., MARTINS, M.H.A., \& DUARTE, R.X. (1997). Estudo da erosão marinha nas praias de Piedade e de Candeias e no estuário de Barra de Jangadas. (154 p.). Município de Jaboatão dos Guararapes-PE. Laboratório de Geologia e Geofísica Marinha- LGGM/ UFPE. Relatório Técnico.

CUTTER, S. E. (1996). Vulnerability to environmental hazard. Progress in Human Geography. 20 (4), 529-539.

DAL CIN, R., \& SIMEONI, U. (1994). A model for determining the classifications vulnerability and risk in the Southern coastal zone of the Marche (Italy). Journal of Coastal Research, 10, 18-29.

LIMA, E. Q. \& AMARAL, R. F. (2013). Vulnerabilidade da zona costeira de Pititinga/RN, Brasil. Vulnerability of coastal zone of Pititinga, Rio Grande do Norte, Brazil. DOI: 10.4215/RM2013.1228. 0010. Mercator, 12(28), 141-153.

LIRA, L., WOR, C., HAZIN, F.H.V., BRAGA JR., H.A.C., \& DOS SANTOS, J.C.P. (2010). Estudo de correntes marinhas por meio do lançamento de cartões de deriva no litoral do estado de Pernambuco, Brasil. Arq. Ciên. Mar, 43(1), 30-37.
MANSO, V.A.V. (1997). Geologia da planície costeira e da plataforma continental interna adjacente da região entre Porto de Galinhas e Tamandaré - litoral Sul de Pernambuco. Porto Alegre RS. (171 p.). Tese de Doutorado em Geociências, Instituto de Geociências, Universidade Federal do Rio Grande do Sul.

MENDONÇA, F. J. B., GONÇALVES, R. M., AWANGE, J., DA SILVA, L. M., \& GREGÓRIO, M. DAS N. (2014). Temporal Shoreline Series Analysis Using Gnss. Boletim de Ciências Geodésicas, 20(3), 701-719. https://dx.doi.org/10.1590/ S1982-21702014000300040

MONTES, M. J.F. (1996). Variação nictemeral do fitoplâcton e parâmetros hidrólogicos no Canal de Santa Cruz, Ilha de Itamaracá, PE. Recife, UFPE, Centro de tecnologia e Geociências. Dissertação de Mestrado em Oceonografia Biológica, $174 p$.

ROCHA, C.P., ARAÚJO, T.C.M., \& MENDONÇA, F.J.B. (2008). Aplicação de técnicas de posicionamento GPS tridimensional para localizar linhas de costa: estudo de caso na praia de Boa Viagem, Recife/PE, Brasil. Revista da Gestão Costeira Integrada, 8(2),127-137.

REIS, C. M. M., NEUMANN, V.H. de L., \& LIMA, E.R.V. (2008). Vulnerabilidade do litoral de João Pessoa (PB) à erosão costeira. Estudos Geológicos, 18(2), 25-36. 